\title{
Chronic Inflammatory Demyelinating Polyneuropathy (CIDP) in a Patient with Diabetes: a primary care perspective
}

Jordan Dever, BS' ${ }^{1}$ Adam M. Franks, MD'1, Laura M. Given, MD', William Rollyson, MD' ${ }^{1}$, Adrienne Mays-Kingston, MD'

ABSTRACT

Chronic inflammatory demyelinating polyneuropathy (CIDP) is a recurrent and progressive disease that causes proximal, symmetrical extremity weakness. The disease is diagnosed using clinical features, electrophysiologic testing, albumino-cytological disassociation in the cerebrospinal fluid, and sural nerve plexus biopsy. However, because of the low sensitivity of diagnostic criteria and other similar neuropathies, including diabetic polyneuropathy (DPN), accurate diagnosis is difficult. Differentiating between these diseases is especially important as CIDP's changes are reversible and DPN's are not. Making this differentiation allows for symptomatic improvement in a patient's quality of life that would not be achieved otherwise. Early recognition and treatment with modalities including corticosteroids, plasmapheresis, and IVIG, demonstrate improvement in a majority of patients. Primary care physicians (PCP) encounter patients with diabetes daily. It is important for PCPs to have a level of familiarity with CIDP to best care for those patients.
Author affiliations are listed at the end of this article.

Correspondence to: Adam Franks, MD Marshall Unviersity Joan C. Edwards School of Medicine franks1@marshall.edu

\section{KEYWORDS}

Chronic Inflammatory Demyelinating Polyneuropathy, CIDP, Diabetic Polyneuropathy, Primary Care

\section{INTRODUCTION}

In 1958, JH Austin identified a cohort of patients suffering from a recurrent, but steroid-responsive, polyneuropathy. ${ }^{1}$ This was officially named chronic inflammatory demyelinating polyneuropathy (CIDP) in 1975 by Peter Dyck. ${ }^{2}$ CIDP is the most common chronic inflammatory neuropathy affecting the peripheral nervous system ${ }^{3}$ and the most common treatable autoimmune neuropathy, accounting for $10 \%$ of patients referred to neurology clinics. ${ }^{4-6}$ Prevalent in 1-9 cases per 100,000 individuals, it tends to occur in adults between $40-60$ years old ${ }^{5,7}$ and affects males $58-66 \%$ of the time., ${ }^{3,4-7}$

The disease can be seen in both humans and other mammals. ${ }^{4}$ It is characterized by progressive, primarily proximal, symmetrical extremity weakness, without muscle wasting. ${ }^{1,2,4-10}$ Like the motor defects, the associated sensory dysfunctions are non-length dependent neuropathies that result in numbness, paresthesia (described as a tingling or buzzing sensation), and proprioception issues. ${ }^{5-7}$ Neuropathic pain is rare and autonomic dysfunction is mild with symptoms usually confined to the bowel and bladder if present at all. ${ }^{5,7,8}$ Symptoms are routinely progressive but one third can have a relapsing and remitting phenotype with the peak severity of symptoms at eight weeks. ${ }^{1-3,5-10}$ Despite criteria from the American Academy of Neurology and European Federation of Neurology Society/Peripheral Nerve Society, diagnosis is difficult owing to their low sensitivities. ${ }^{3}$ These criteria depend upon clinical features, electrophysiologic testing, albuminocytological disassociation in the cerebrospinal fluid (CSF), sural nerve plexus biopsy and MRI. ${ }^{6,8}$ Atypical forms of CIDP further compound this diagnostic dilemma, with many patients carrying the diagnosis without fulfilling the criteria. ${ }^{1,711}$ Diagnostic certainty is complicated by CIDP mimics (Table \#1) and other common concomitant neurologic conditions like diabetic polyneuropathy (DPN). Familiarity with the pathology and clinical course of CIDP is important for primary care physicians (PCPs) to make the 


\begin{tabular}{|c|c|c|c|c|c|c|}
\hline \multicolumn{7}{|c|}{ Demyelinating Polyneuropathy Signs and Symptoms } \\
\hline & $\begin{array}{l}\text { Peak } \\
\text { Symptoms }\end{array}$ & Progression & Relapses & $\begin{array}{l}\text { Motor } \\
\text { Symptoms }\end{array}$ & $\begin{array}{l}\text { Sensory } \\
\text { Symptoms }\end{array}$ & $\begin{array}{l}\text { Autonomic } \\
\text { Symptoms }\end{array}$ \\
\hline $\begin{array}{l}\text { CIDP } \\
\text { (Chronic } \\
\text { Inflammatory } \\
\text { Demyelinating } \\
\text { Polyneuropathy) }\end{array}$ & 8 weeks & Yes & Yes & $\begin{array}{l}\text { Symmetric } \\
\text { proximal limb } \\
\text { weakness }\end{array}$ & $\begin{array}{l}\text { Numbness, } \\
\text { paresthesias, } \\
\text { proprioception } \\
\text { loss, areflexia }\end{array}$ & $\begin{array}{l}\text { Rare (bowel or } \\
\text { bladder) }\end{array}$ \\
\hline $\begin{array}{l}\text { A-CIDP } \\
\text { (Acute - Chronic } \\
\text { Inflammatory } \\
\text { Demyelinating } \\
\text { Polvneuropathv) }\end{array}$ & $<8$ weeks & Yes & Yes & More aggressive & $\begin{array}{l}\text { More } \\
\text { proprioception } \\
\text { issues }\end{array}$ & $\begin{array}{l}\text { Rare (bowel or } \\
\text { bladder) }\end{array}$ \\
\hline $\begin{array}{l}\text { AIDP } \\
\text { (Acute } \\
\text { Inflammatory } \\
\text { Demyelinating } \\
\text { Polyneuropathy) }\end{array}$ & 4 weeks & No & Only with TRF & $\begin{array}{l}\text { Less aggressive; } \\
\text { Can be } \\
\text { descending }\end{array}$ & & $\begin{array}{l}\text { Rare (bowel or } \\
\text { bladder) }\end{array}$ \\
\hline SIDP & 4 weeks & $\begin{array}{l}\text { Yes } \\
\text { (Monophasic) }\end{array}$ & No & None & & \\
\hline $\begin{array}{l}\text { GBS } \\
\text { (Guillain Barre } \\
\text { Syndrome) }\end{array}$ & 4 weeks & $\begin{array}{l}\text { No } \\
\text { (monophasic) }\end{array}$ & Only with TRF & $\begin{array}{l}\text { More } \\
\text { aggressive; } 2 / 3 \\
\text { preceded by } \\
\text { illness; Involves } \\
\text { Bulbar, } \\
\text { Respiratory and } \\
\text { Autonomic } \\
\text { systems }\end{array}$ & & Present \\
\hline $\begin{array}{l}\text { DPN } \\
\text { (Diabetic } \\
\text { Polvneuropathv) }\end{array}$ & $>1$ year & Yes & No & None & $\begin{array}{l}\text { Bilateral, distal, } \\
\text { symmetric pain }\end{array}$ & Present \\
\hline $\begin{array}{l}\text { Entrapment } \\
\text { Neuropraxia }\end{array}$ & $\begin{array}{l}\text { Months to } \\
\text { year; Can be } \\
\text { acute }\end{array}$ & No & No & Yes & Yes & No \\
\hline
\end{tabular}

TABLE \# 1: Symptom comparison of different demyelinating polyneuropathies.

correct diagnosis and ensure rapid and appropriate treatment.

\section{CASE PRESENTATION}

A 49-year-old male with chronic low back pain and a seven-year history of diabetic peripheral neuropathy resulting from twenty years of poorly controlled type 2 diabetes, presented to his PCP complaining of a two-week history of worsening pain and weakness. Prior to this, the patient had complaints of progressive neuropathic pain and failed multiple trials of medications, including opiates. Ultimately, he had a spinal cord stimulator implanted. The patient reported "lightning [shooting] down both legs" causing weakness with weight-bearing as well as falls. Following the appointment with his PCP, the patient was immediately sent to pain management for the evaluation of the stimulator. CT imaging of the lumbar and thoracic spine was ordered at the request of the pain management specialist. This revealed no acute changes and appropriate placement of the spinal cord stimulator. Neurology was consulted and ordered an electromyogram and nerve conduction study of the lower extremities. The initial impression was severe diabetic neuropathy.

The neurologist referred the patient to a colleague and repeat electrophysiologic testing at six weeks following the initial presentation showed 'very severe chronic axonal sensory-motor neuropathy' and further testing was recommended of the upper extremities, which demonstrated a demyelinating neuropathy. Evaluation by neurology included thyroid levels, RPR, vitamin B12, copper, ganglioside antibodies and serum electrophoresis, which returned as normal. Sedimentation rate, homocysteine, methyl-malonic acid, and free Kappa/ 
Lambda light chains were elevated, while vitamin B6 and zinc levels were low. A normal opening pressure of $33 \mathrm{mmHg}$ on lumbar puncture was obtained.

Red and white blood cells were normal within the cerebrospinal fluid (CSF), and both glucose (90 $\mathrm{mg} / \mathrm{dL}$ ) and protein $(55 \mathrm{mg} / \mathrm{dL}$ ) were elevated. Electrophysiologic testing of the bilateral upper extremities was consistent with CIDP (Figures \#1 \& \#2).

His chronic kidney disease and poorly controlled diabetes limited the use of IVIG and high-dose steroids. Therefore, he began treatment with five inpatient sessions of plasma exchange (PLEX) and physical therapy. Within two weeks, increased lower extremity strength, decreased pain, and unassisted ambulation was noted. One month after the initial treatment, he received a second course of five PLEX treatments. By six-weeks following the second treatment, the patient noted continued improvement in symptoms with decreased pain and increased range of motion. This lasted three months. A functional decline in strength and an increase in limb paresthesias necessitated a third round of PLEX
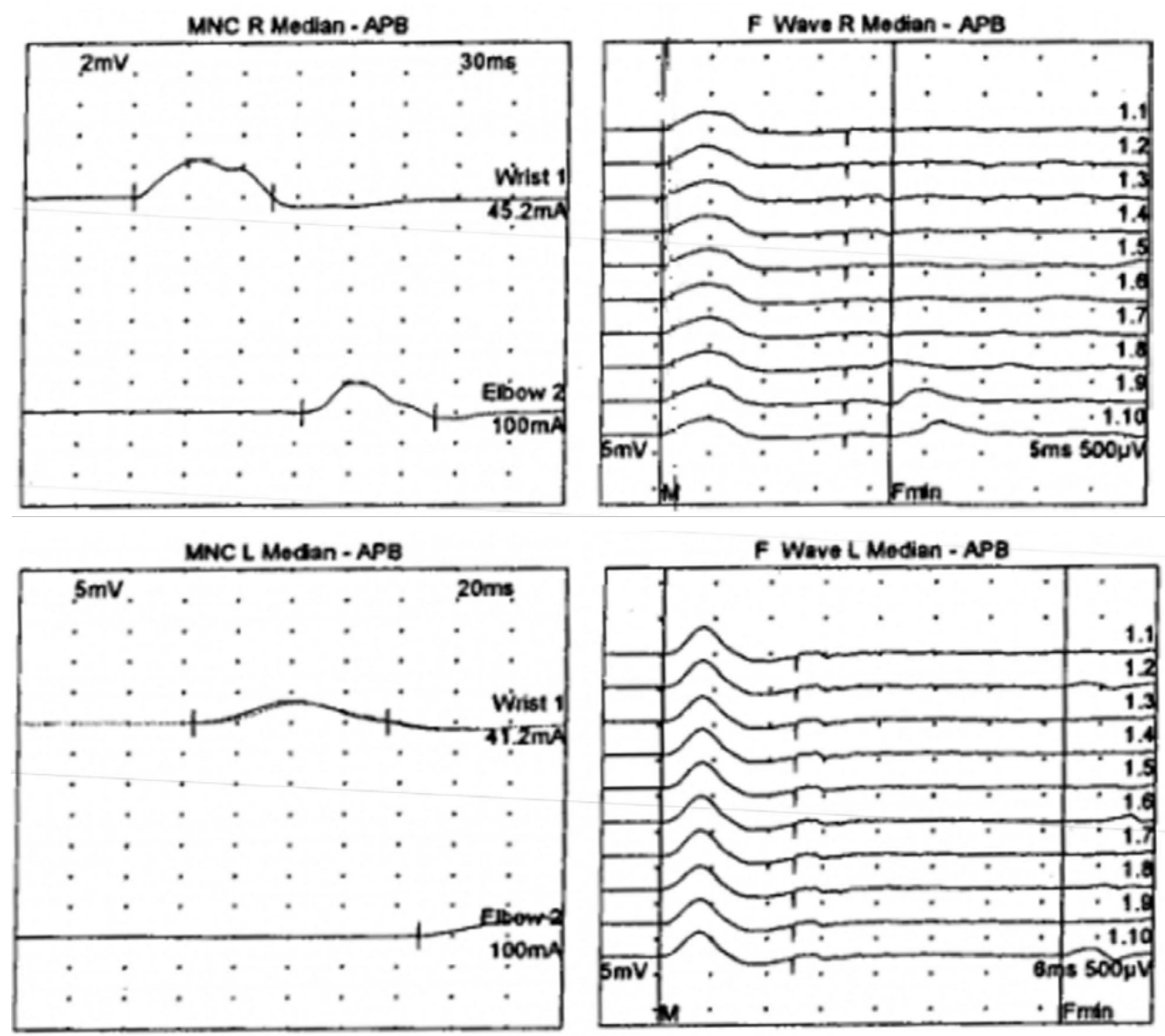

FIGURE 1: Nerve Conduction Study - Motor (left column) and F-Wave (right column) complexes for bilateral median nerves. The motor nerve conduction (MNC) of bilateral median nerves was tested using the abductor pollicis brevis (APB). Amplitude is related to the number of axons in a nerve, therefore a reduction in amplitude indicates a loss of neurons. Latency is a marker of time and when prolonged, signifies a demyelinating process. Conduction velocity, a measure of speed, is affected by both axonal loss and demyelination. $F$ waves evaluate proximal demyelination by looking at conduction speeds. F waves are created when a stimulus is applied to a distal motor nerve. The impulse travels antidromically from peripheral nerve to anterior horn cell and is bounced back down the motor neuron to create muscle contraction. In early disease course, F waves may be normal. In mid-course of disease, F waves will show delayed latency. In late/severe disease, F waves may be absent. In our patient, the left median motor amplitude was reduced with a prolonged distal motor latency and a moderately slow conduction velocity in the demyelinating range. The left median $\mathrm{F}$ wave latency was very prolonged, indicating proximal demyelination. The right median motor amplitude was moderately reduced, with a prolonged distal motor latency and very slowed conduction velocity registering in the demyelinating range. The right median F wave latency was normal. 

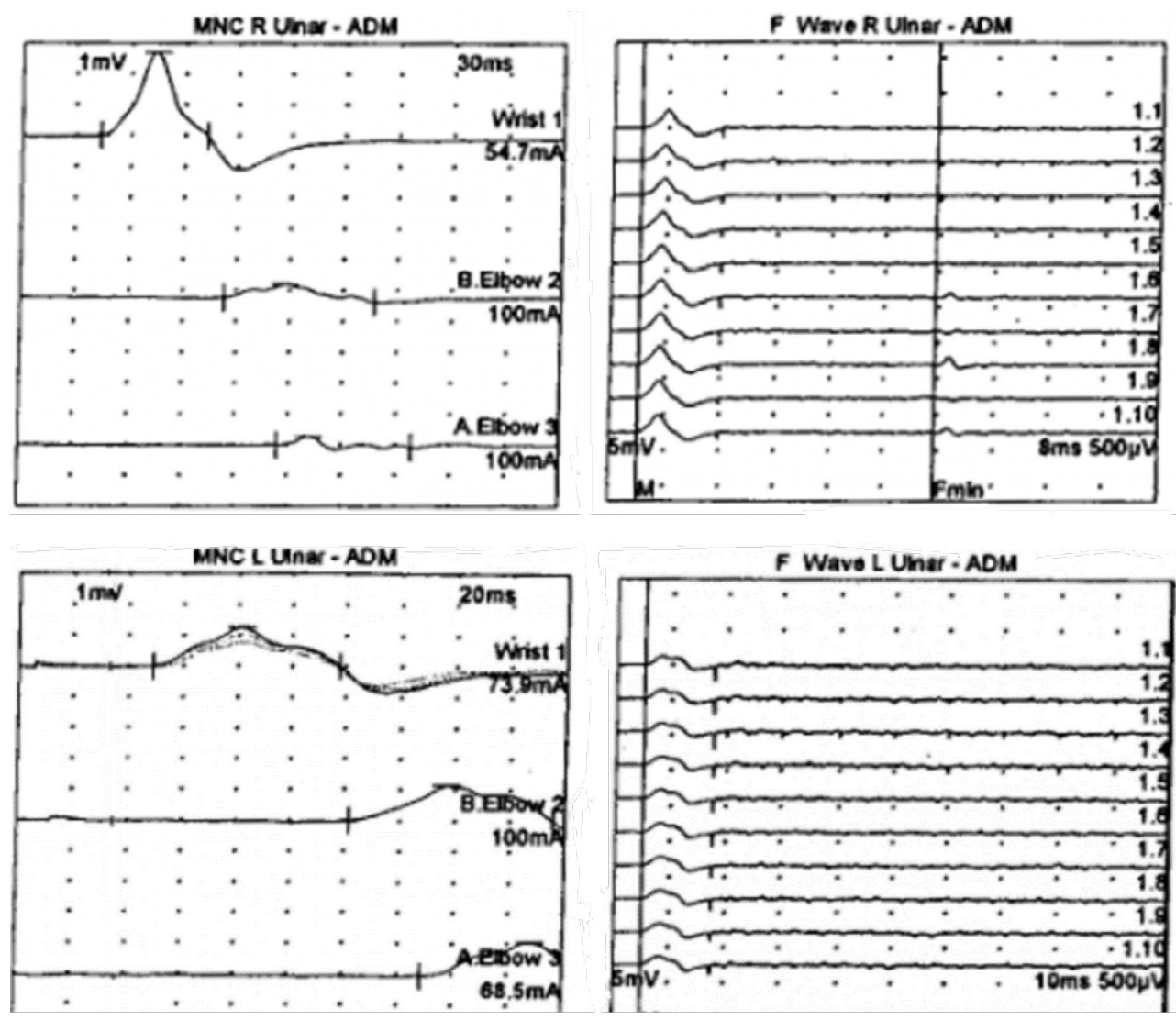

FIGURE 2: Nerve Conduction Study - Motor (left column) and F-Wave (right column) complexes for bilateral ulnar nerves. The motor nerve conduction (MNC) of bilateral ulnar nerves was tested using the abductor digiti minimi (ADM). The left ulnar motor amplitude was very reduced with a prolonged distal motor latency and moderately slow conduction velocities indicating demyelination and loss of axons. The left ulnar $F$ wave response was absent indicating late/severe disease progression. The right ulnar motor amplitude demonstrated a conduction block at the elbow, with prolonged distal motor latency and slowed conduction velocities in the demyelinating range. A conduction block occurs when the loss of myelin thickness is great enough to lead to saltatory conduction failure and severely prolonged motor latencies and conduction velocity. The right ulnar $F$ wave latency was also prolonged.

treatments. The patient improved, but not to his previous level of functioning, and left the hospital requiring a walker to ambulate. One month later, the patient passed away suddenly at home from a hypoxic episode.

\section{DISCUSSION}

\section{CIDP Pathophysiology AND Diagnosis}

CIDP is classified as a demyelinating process of the peripheral nervous system..$^{2,4-6,10,13}$ The precise pathological mechanisms are still largely unknown despite treatment based studies rendering genetic, metabolic, and toxic causes unlikely. ${ }^{12}$ Cell-mediated and humoral immune-mediated inflammation directed against the peripheral nerve epitopes of myelin sheath Schwann Cells are implicated for this polyradiculoneuropathy. ${ }^{1,3}$ Cell-mediated and humoral influenced $T$ cells affect the permeability of the blood-nerve barrier, allowing antibodies to attack the endoneurium. ${ }^{6}$ The Schwann cells begin to react to this damage and lay down a new myelin sheath. This demyelinating-remyelinating picture primarily targets proximal peripheral nerves, specifically spinal roots, proximal nerve trunks, and major plexuses. ${ }^{2,4-6,12,13}$ 
Despite only $50 \%-60 \%$ of patients with CIDP fulfilling one of the over fifteen established criteria, 2,5,7 components of these criteria do have merit and can help aid the physician in early diagnosis. One such component is electrophysiologic testing (Table \#2), which demonstrates primary demyelination by reduced conduction velocities, prolonged distal motor latencies, prolonged $\mathrm{F}$ wave latencies, and a patchy temporal dispersion, or conduction blockade..$^{2,-6,13}$ Secondly, CSF studies reveal an albumin-cytologic disassociation, with increased protein levels from damage to the blood-CSF barrier at proximal nerve roots. ${ }^{5,6,10,14}$ To further emphasize the inflammatory nature of CIDP, fibrinogen, haptoglobin and prealbumin, all indicators of chronic and acute inflammation, are seen in the CSF. ${ }^{14}$ Finally, a nerve biopsy of affected proximal sensory nerves is diagnostic but should be saved for last resort. ${ }^{5,6,12,13}$ Microscopic evaluation of biopsies from patients show macrophage associated demyelinationremyelination, endoneurial infiltrates of $\mathrm{CD} 8+$ and CD4+ $T$ cells, hypermyelination formation of 'onion bulbs', axonal degeneration, edema, and deposition of complement and immunoglobulin. ${ }^{2,4-6,12,13}$

\begin{tabular}{|c|c|c|c|c|c|}
\hline \multicolumn{6}{|c|}{ Comparison of Results on Nerve Conduction Studies } \\
\hline & $\begin{array}{l}\text { Conduction } \\
\text { Velocities }\end{array}$ & \begin{tabular}{|l} 
Distal Motor \\
Latencies
\end{tabular} & $\begin{array}{l}\text { F Wave } \\
\text { Latencies }\end{array}$ & Dispersion & $\begin{array}{l}\text { Amplitude of } \\
\text { CMAP }\end{array}$ \\
\hline $\begin{array}{l}\text { CIDP } \\
\text { (Chronic } \\
\text { Inflammatory } \\
\text { Demyelinating } \\
\text { Polyneuropathy) }\end{array}$ & Decreased & Prolonged & Prolonged & $\begin{array}{l}\text { Conduction } \\
\text { block or } \\
\text { temporal } \\
\text { dispersion } \\
\text { (distortion of } \\
\text { amplitude/peak) }\end{array}$ & $\begin{array}{l}\text { Decreased if CB } \\
\text { or axonal loss is } \\
\text { present }\end{array}$ \\
\hline $\begin{array}{l}\text { A-CIDP } \\
\text { (Acute - Chronic } \\
\text { Inflammatory } \\
\text { Demyelinating } \\
\text { Polyneuropathy) }\end{array}$ & Decreased & Prolonged & Prolonged & Yes & $\begin{array}{l}\text { Decreased if CB } \\
\text { or axonal loss is } \\
\text { present }\end{array}$ \\
\hline $\begin{array}{l}\text { AIDP } \\
\text { (Acute } \\
\text { Inflammatory } \\
\text { Demyelinating } \\
\text { Polyneuropathy) }\end{array}$ & Decreased & Prolonged & Prolonged & Yes & \\
\hline SIDP & Decreased & Prolonged & Prolonged & Yes & Decreased \\
\hline $\begin{array}{l}\text { GBS } \\
\text { (Guillain Barre } \\
\text { Syndrome) }\end{array}$ & Decreased & Prolonged & Prolonged & Yes & \\
\hline $\begin{array}{l}\text { DPN } \\
\text { (Diabetic } \\
\text { Polyneuropathy) }\end{array}$ & Decreased & Prolonged & $\begin{array}{l}\text { Prolonged if } \\
\text { disease } \\
\text { progressed to } \\
\text { proximal nerves. }\end{array}$ & $\begin{array}{l}\text { Yes if } \\
\text { demyelination is } \\
\text { present }\end{array}$ & $\begin{array}{l}\text { Decreased if CB } \\
\text { or axonal loss is } \\
\text { present }\end{array}$ \\
\hline $\begin{array}{l}\text { Axonal } \\
\text { Neuropathies }\end{array}$ & $\begin{array}{l}\text { Normal to } \\
\text { slight } \\
\text { decrease }\end{array}$ & $\begin{array}{l}\text { Relatively } \\
\text { normal }\end{array}$ & - & No & $\begin{array}{l}\text { Significantly } \\
\text { Decreased }\end{array}$ \\
\hline $\begin{array}{l}\text { Entrapment } \\
\text { Neuropathies }\end{array}$ & $\begin{array}{l}\text { Decreased } \\
\text { above lesion, } \\
\text { normal below }\end{array}$ & $\begin{array}{l}\text { Prolonged if } \\
\text { above lesion }\end{array}$ & $\begin{array}{l}\text { Can pinpoint to } \\
\text { area of lesion }\end{array}$ & No & Normal \\
\hline
\end{tabular}

TABLE \#2: EMG comparison of different demyelinating polyneuropathies. LLN = lower limit normal; ULN = upper limit normal. Conduction Velocities = Segment Distance $(\mathrm{mm})$ per change of Segment Latency (msec). Distal Motor Latencies $(\mathrm{msec})=$ the time from stimulus to the distal motor response is recorded. Distal motor nerves have tortuous routes. $H$ Wave: the electrical equivalent of the monosynaptic stretch reflex. Stimulate 1 a fibers to dorsal root ganglion to anterior horn cells to alpha motor axon to muscle. $F$ Wave: long latency muscle action potential seen after maximal stimulation to a nerve. Stimulus travels through motor fibers to anterior horn cells, depolarized at critical time, to alpha motor axon to small late motor/muscle response. Seen AFTER the direct motor response. Used to test proximal nerve abnormalities. Temporal Dispersion = Seen in incomplete demyelination allowing conduction at different velocities. (CMAP) compound motor action potential $=$ activation of muscle fibers in a target muscle supplied by the nerve. 


\section{Diagnostic Mimics of CIDP}

Differentiating between the diagnosis of CIDP and the alphabet soup of other immune-mediated demyelinating neuropathies (Table \#1) is difficult due to the overlapping, and sometimes inconsistent, set of neurologic symptoms. ${ }^{2,5}$ Guillain-Barre syndrome (GBS) is the most frequently pursued diagnostic option but can be differentiated best by the time frame and course in which the symptoms develop. ${ }^{5,10,12} \mathrm{GBS}$ reaches its maximum severity in a four-week monophasic course, ${ }^{8,15}$ whereas CIDP reaches its maximum severity through either a progressive (two-thirds of cases) or a relapsingremitting course (one-third of cases) in eight weeks. ${ }^{1,4-9}$ Adding another layer of confusion, treatment-related failures of GBS can mimic the relapsing-remitting course of CIDP. ${ }^{15}$ Two atypical variants of CIDP further complicate using the clinical course for diagnosis. Acute CIDP (a-CIDP), occurring in $16 \%$ of CIDP patients, ${ }^{15}$ and acute inflammatory demyelinating polyneuropathy (AIDP), exhibit similar symptoms, but with peak severity closer to four weeks. ${ }^{4,7,8}$ The nature of symptoms can also vary. GBS tends to exhibit more severe symptoms like respiratory failure and will be more likely to exhibit autonomic dysfunction and cranial nerve involvement.,12 Patients with A-CIDP, AIDP and CIDP rarely present with these findings, although AIDP tends to be the most severe of the three. ${ }^{7,8,15}$ Diagnostic overlap can be seen with electrophysiologic testing and CSF studies (Table \#2), ${ }^{8,9,14,15}$ but GBS tends to develop after infections, especially with Campylobacter jejuni and Zika virus. $^{6,15}$

\section{Diabetic PolyneUROPATHY - COMPOUNDING DIAGNOSTIC CERTAINTY}

In this case, the diagnosis of the patient's longstanding neuropathy was further confounded by the presence of diabetes, which affects $9 \%$ of the general population and $29.6 \%$ of those people 65 years and older. ${ }^{6}$ Severe or uncontrolled cases of diabetes can lead to diabetic peripheral neuropathy (DPN).7 DPN, the most common peripheral polyneuropathy, results from axonal damage due to glycemic mediated metabolic derangement. This glucose-mediated process is thought to disturb neuronal metabolism, alter blood supply to the vasa nervosum, and inflict damage to the Schwann Cells of the nerve sheath. ${ }^{2}$ An autoimmune response can occur through non-enzymatic glycosylation of myelin, whereby this glycosylation promotes recognition and degradation by macrophages. ${ }^{1}$ While the pathology is different, DPN shares some symptoms with CIDP, not only making it challenging to distinguish between the two, but also masking and augmenting symptoms of CIDP. Clues to differentiate the two clinical pictures include DPN's gradual (greater than one year) progression of axonal length-dependent symptoms, which tend to be mostly sensory in nature and predominately affect distal lower extremities. ${ }^{2}$

Electrophysiologic results (Table \#2) and protein levels in the CSF create further overlap due to similar findings. ${ }^{2,6}$ Another problem with DPN is its ability to mask concomitant CIDP as the patient concentrates more on their pain than the change in weakness and other neurologic symptoms. ${ }^{6} \mathrm{~A}$ combination should be suspected in an older population, especially when the symptoms and conduction velocities of DPN are out of proportion for the duration of diabetes and level of diabetic control. ${ }^{2,3,6}$ This requires a certain level of clinical suspicion based upon comparisons to neuropathic symptom burdens of similar patients with only diabetes. While diagnostic criteria are less predictive, decreasing the likelihood of treatment initiation, treatment success rates in patients with DPN and CIDP combined are similar to those of CIDP alone. ${ }^{3,6}$

IMPORTANCE OF RAPID AND CORRECT Diagnosis

The most important reason to correctly differentiate a diabetic patient with concomitant CIDP from worsening DPN is that unlike irreversible DPN, CIDP is a treatable condition. ${ }^{2}$ The case-patient had a prolonged course of sensory symptoms related to DPN. Worsening neuropathic symptoms and weakness occurred around the implantation of the spinal cord stimulator. It is unclear how long the patient's CIDP was masked by his DPN. It wasn't until the new neurologic symptoms, initially attributed to the stimulator, that the diagnosis was uncovered by the subsequent neurologic evaluation. Clues for earlier evaluation by the PCP could have been that the patient's sensory symptoms were refractory to standard treatment, along with the development of motor dysfunction and proximal weakness. 
Treatment for CIDP patients with diabetes is guided by the treatment methodologies for CIDP alone, with goals to decrease handicap, reduce symptoms, and maintain long-term remission. ${ }^{5,7}$ Traditional therapy for CIDP includes corticosteroids, plasmapheresis, and IVIG. Improvement is seen in $50-80 \%$ of patients. ${ }^{5}$ Corticosteroid benefit is similar for progressive and relapsing-remitting types and is effective at $60 \mathrm{mg}$ daily doses of Prednisone. ${ }^{5}$ Responses are noted as early as two months, peaking in efficacy at six months. There is a seventy percent relapse after discontinuation. ${ }^{5,6}$ However, because corticosteroids can worsen glycemic control in patients with diabetes, as well as impact osteoporosis, gastritis, cataracts, mood changes, glaucoma and fluid retention, IVIG and plasmapheresis are appealing options. ${ }^{5}$ Plasmapheresis can remove up to $45 \%$ of pathogenic humoral factors in a single exchange, affording a $33-80 \%$ response rate. ${ }^{5}$ IVIG is usually the preferred treatment, especially for severe cases, and can modulate pathogenic autoantibodies, suppress pathogenic cytokines, reduce complement deposition, and alternate pathogenic T cell function. ${ }^{5}$ There is a $50-75 \%$ response rate within a few weeks, which results in improved strength, functional disability and quality of life. ${ }^{5}$ Complications for these treatments are the expense, time consumption, availability, and side effects ranging from headache, rash and flu-like symptoms to volume overload, hemolytic anemia and transient neutropenia. ${ }^{5}$

\section{CONCLUSION}

CIDP in the presence of DPN is a difficult diagnosis for a PCP to suspect. Recognizing it from other potential neuropathies increased the likelihood of appropriate treatment of symptoms and improvement in the patient's quality of life. Early diagnosis requires clinical suspicion. While specialist involvement is essential, PCPs usually will be the first to encounter this pathology and differentiate it from the multiple mimics. PCPs should consider CIDP superimposed on DPN when a diabetic patient has proximal weakness and sensory symptoms refractory to usual treatments and/or are disproportionately greater than would be expected for the duration of diabetes and the level of glucose control.

\section{AUTHOR AFFILIATIONS}

1. Marshall University Joan C. Edwards School of Medicine, Huntington, West Virginia

\section{REFERENCES}

1. Rotta FT, Sussman AT, Bradley WG, Ram Ayyar D, Sharma KR, Shebert RT. The spectrum of chronic inflammatory demyelinating polyneuropathy. J Neurol Sci. 2000;173(2):129-139.

2. Lotan I, Hellman MA, Steiner I. Diagnostic criteria of chronic inflammatory demyelinating polyneuropathy in diabetes mellitus. Acta Neurol Scand. 2015;132(4):278-283.

3. Dunnigan SK, Ebadi $H$, Breiner $A$, et al. The characteristics of chronic inflammatory demyelinating polyneuropathy in patients with and without diabetes--an observational study. PLoS One. 2014;9(2):e89344.

4. Mathey EK, Park SB, Hughes RA, et al. Chronic inflammatory demyelinating polyradiculoneuropathy: from pathology to phenotype. J Neurol Neurosurg Psychiatry. 2015;86(9):973-985.

5. Gorson KC. An update on the management of chronic inflammatory demyelinating polyneuropathy. Ther Adv Neurol Disord. 2012;5(6):359-373.

6. Schafflick D, Kieseier BC, Wiendl H, Meyer Zu Horste G. Novel pathomechanisms in inflammatory neuropathies. J Neuroinflammation. 2017;14(1):232.

7. Neligan A, Reilly MM, Lunn MP. CIDP: mimics and chameleons. Pract Neurol. 2014;14(6):399-408.

8. Sung JY, Tani J, Park SB, Kiernan MC, Lin CS. Early identification of 'acute-onset' chronic inflammatory demyelinating polyneuropathy. Brain. 2014;137(Pt 8):2155-2163.

9. Alessandro L, Pastor Rueda JM, Wilken M, et al. Differences between acute-onset chronic inflammatory demyelinating polyneuropathy and acute inflammatory demyelinating polyneuropathy in adult patients. J Peripher Nerv Syst. 2018;23(3):154-158.

10. Mygland A, Monstad P. Chronic acquired demyelinating symmetric polyneuropathy classified by pattern of weakness. Arch Neurol. 2003;60(2):260-264. 
11. Lucke IM, Peric S, van Lieverloo GGA, et al. Elevated leukocyte count in cerebrospinal fluid of patients with chronic inflammatory demyelinating polyneuropathy. J Peripher Nerv Syst. 2018;23(1):49-54.

12. Hantson P, Kevers L, Fabien N, Van Den Bergh P. Acute-onset chronic inflammatory demyelinating polyneuropathy with cranial nerve involvement, dysautonomia, respiratory failure, and autoantibodies. Muscle Nerve. 2010;41(3):423-426.

13. Molin J, Marquez M, Raurell X, Matiasek K, Ferrer I, Pumarola M. Acute clinical onset chronic inflammatory demyelinating polyneuropathy in a dog. Muscle Nerve. 2011;44(3):441-444.

14. Zhang HL, Zhang XM, Mao XJ, et al. Altered cerebrospinal fluid index of prealbumin, fibrinogen, and haptoglobin in patients with Guillain-Barre syndrome and chronic inflammatory demyelinating polyneuropathy. Acta Neurol Scand. 2012;125(2):129-135.

15. Ruts L, Drenthen J, Jacobs BC, van Doorn PA. Distinguishing acute-onset CIDP from fluctuating Guillain-Barre syndrome: a prospective study. Neurology. 2010;74(21):1680-1686. 